\title{
Hourly and daily variations of xylem sapflow in sweet chestnut coppices using a thermal measurement method
}

\author{
V. Bobay and B. Saugier \\ Laboratoire d'Ecologie végétale, bât. 362, Université Paris-XI, 91405 Orsay, France
}

\section{Introduction}

A new method for measuring xylem sapflow (Granier, 1985) has been tested to calculate forest transpiration. Two coppices of sweet chestnut (Castanea sativa Mill.) in the south of lle-de-France were studied. One of them was thinned to a density of 3500 stems/ha, the other $(6000$ stems/ha) was used as a control.

This paper presents preliminary results of hourly and daily variations of xylem sapflow in the thinned coppice.

\section{Materials and Methods}

A xylem sapflow measurement sensor comprises two cylindrical probes inserted into the conducting xylem of the trunk. One of the probes is heated at constant power, the other is unheated and used as a reference. The temperature difference between both probes is a measure of sap velocity around the heated probe. It is recorded using differential thermocouples connected to a data logger. This method allows investigations of the variability of the sap velocity within a stem or between stems. Sapflow is calculated with the following formula and may be averaged on hourly or daily time scales (Bobay and Granier, 1987): $F=$ $42.84 \times S A \times K^{1.231}$; where $F=$ sapflow $\left(\mathrm{cm}^{3} \cdot \mathrm{h}^{-1}\right) ; S A=$ sapwood area at heated probe level $\left(\mathrm{cm}^{2}\right) ; K=$ flow index (without dimensions). $K=[\Delta T M-\Delta T(u)] / \Delta T(u) ;$ where $\Delta T M=$ temperature difference without any sapflow $\left({ }^{\circ} \mathrm{C}\right) ; \Delta T(u)=$ ternperature difference with sapflow $u\left({ }^{\circ} \mathrm{C}\right)$.

Psychrometer and net-radiometer were installed on a tower in the thinned coppice. Potential evapotranspiration $E_{\mathrm{p}}$ was calculated using Priestley-Taylor's equation (1972), with a hourly time step:

$E_{p}=1.26 \times(\Delta /(\Delta+\gamma)) \times(R n / \lambda)$

where $R n=$ net radiation $\left(\mathrm{W} \cdot \mathrm{m}^{-2}\right) ; \Delta=$ change of saturation vapor pressure per ${ }^{\circ} \mathrm{C}\left(\mathrm{kPa}^{\circ} \mathrm{C}^{-1}\right)$; $\gamma=$ psychrometer constant $\left(\mathrm{kPa}^{\circ}{ }^{\circ} \mathrm{C}-1\right) ; \lambda=$ latent heat of vaporization of water $\left(J \cdot \mathrm{g}^{-1}\right)$.

Use of this equation is not usually recommended for forests but was found useful in chestnut coppices that have large leaves and a relatively large boundary layer resistance.

\section{Results and Discussion}

Hourly variations of xylem sapflow were recorded and compared during days with different irradiances.

On 5 July 1987, a sunny day, maximum $\left(T_{\max }\right)$ and minimum $\left(T_{\min }\right)$ temperatures 


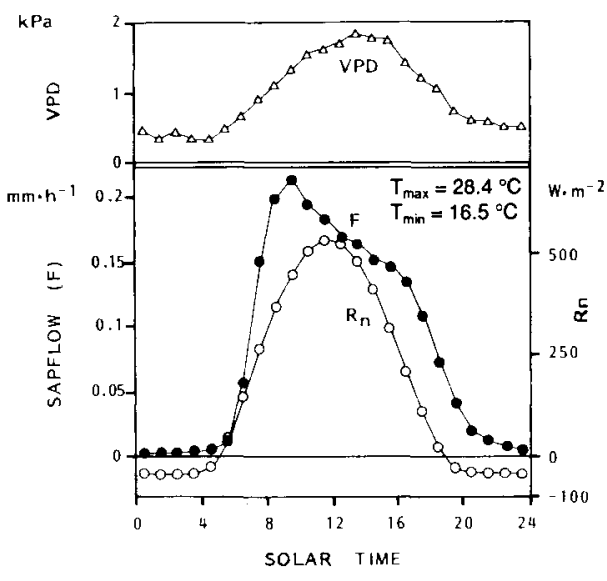

Fig. 1. Hourly variations of xylem sapflow $(F)$, net radiation $(R n)$ and vapor pressure deficit (VPD) on 5 July 1987.

were respectively $28.4^{\circ} \mathrm{C}$ and $16.5^{\circ} \mathrm{C}$, with a global radiation $R g$ of $2637 \mathrm{~J} \cdot \mathrm{cm}^{-2} \cdot \mathrm{d}^{-1}$ and a sapflow of $2.05 \mathrm{~mm} \cdot \mathrm{d}^{-1}$ (Fig. 1). By contrast, on 31 July 1987, a cloudy day, $T_{\text {max }}=20.6^{\circ} \mathrm{C}, T_{\min }=12.2^{\circ} \mathrm{C}, R g=744$ $3 \cdot \mathrm{cm}^{-2} \cdot \mathrm{d}^{-1}$ and sapflow $=0.8 \mathrm{~mm} \cdot \mathrm{d}^{-1}(\mathrm{Fig}$. 2). Both Figs. 1 and 2 show an influence of net radiation on sapflow variations. With a daily time step, transpiration $T$ is about equal to sapflow, as was shown by measurements of weight loss and water uptake by cut stems.

Using sensors in 7 stems, the sapflow of the whole coppice was computed and plotted against the vapor pressure deficit (VPD) (Fig. 3). The relationship is quite good and reveals an apparent limit to forest transpiration.

Daily variations of sapflow $F$ and $E_{\mathrm{p}}$ are shown in Fig. 4. Because of a particularly wet season, no water stress was found during 1987. The maximum transpiration was $2.58 \mathrm{~mm} \cdot \mathrm{d}^{-1}$. This is quite low in comparison with $E_{\mathrm{p}}$ values that reach 6 $\mathrm{mm} \cdot \mathrm{d}^{-1}$. This may be due to a low leaf area index (2.8) caused by thinning and also by poor weather.

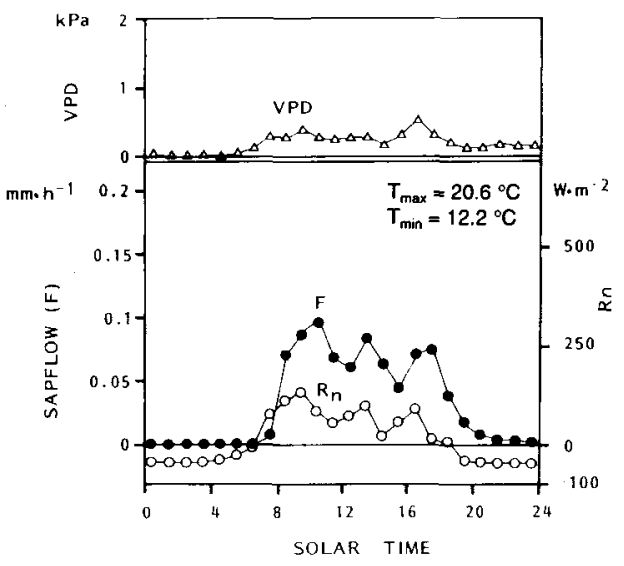

Fig. 2. Hourly variations of xylem sapflow $(F)$, net radiation $(R n)$ and vapor pressure deficit (VPD) on 31 July 1987.

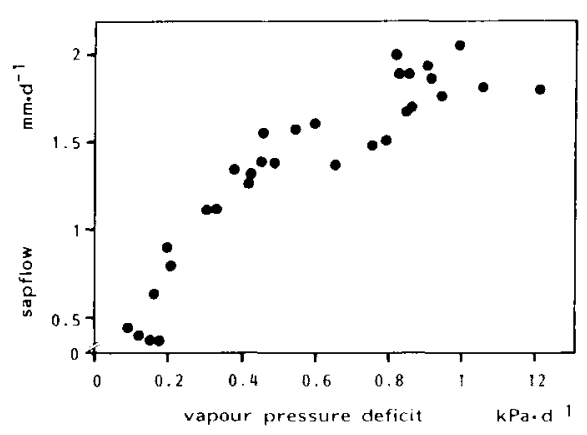

Fig. 3. Relationship between the xylem sapflow of the whole coppice and the vapor pressure deficit in July 1987.

\section{Conclusion}

The method used here enabled continuous measurements of forest transpiration throughout the entire growing season. These results will be compared to a soilwater balance approach using a neutron probe and rainfall measurements. The data will be further analyzed in order to derive a forest transpiration model. 


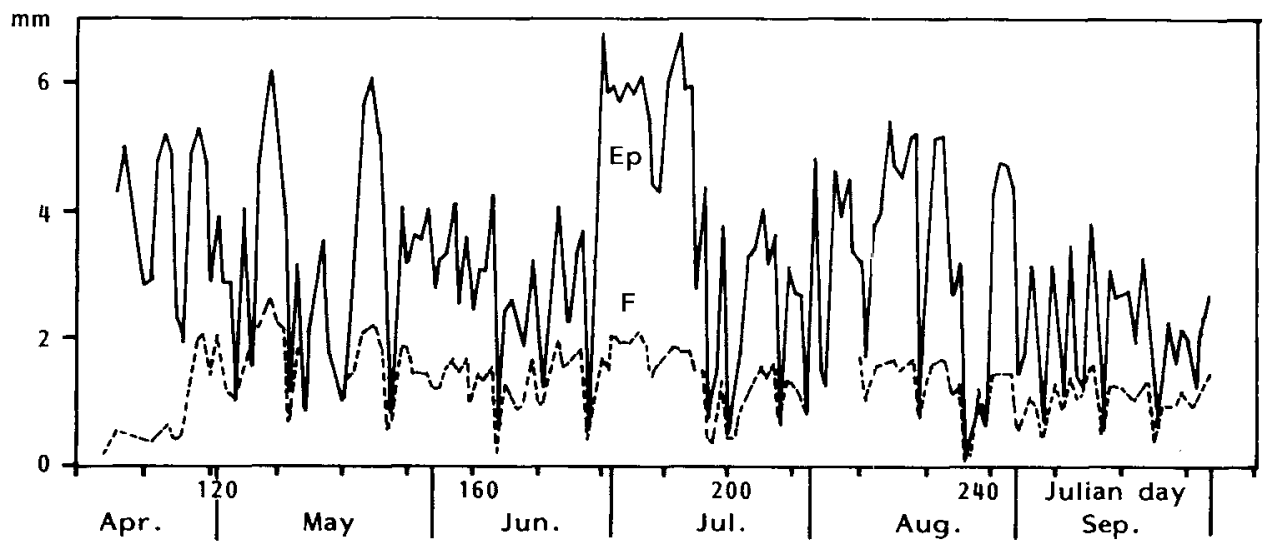

Fig. 4. Daily variations of sapflow $\left(F, \mathrm{~mm} \cdot \mathrm{d}^{-1}\right)$ and potential evapotranspiration $\left(E_{\mathrm{p}}, \mathrm{mm} \cdot \mathrm{d}^{-1}\right)$ calculated with Priestley-Taylor's equation.

\section{References}

Bobay V. \& Granier A. (1987) Etude de la transpiration d'un taillis de châtaignier à l'aide d'une nouvelle méthode thermique de mesure du flux de sève. Bull. Group. Fr. Humidimetrie Neutronique 21, 33-44
Granier A. (1985) Une nouvelle méthode pour la mesure du flux de sève brute dans le tronc des arbres. Ann. Sci. For. 42, 81-88

Priestley C.H. \& Taylor R.J. (1972) On the assessment of surface heat flux and evaporation using large scale parameters. Mon. Weather Rev. 100, 81-92 